\title{
板紙の共重合分岐型紙力剤の使用経験*
}

王子製紙株式会社 佐賀工場研究技術室 岸 川強

\section{Operating Experiment of High-Density Dry Strength Agent for Paper Board}

Tsuyoshi Kishikawa

Saga Mill, Oji Paper Co. Ltd.

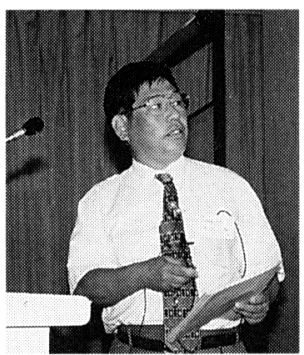

For a few years, there is a tendency in paper industry that saving energy, increasing the rate of waste paper applied and making paperboard light-weight are making progress. Besides, we have seen that higher operating speed of paper machine for the improvement of productivity, and higher closed rate on waste water treatment in the paper making system. On the other hand, we can see variety of needs and demanding higher quality for paper board coming from the market at the same time. In order for paper mills to cope with such requirements, considering the tendency on environmental issue above mentioned, it is required to improve the quality and application know-how of dry paper strengthening agent.

This is reported on the development of introduction and result of "Mix (anionic/ amphibiatic PAM)" and its succeeding "Co-polymer of High-Density Dry Strength Agent" and described the summary.

\section{1.はじめに}

この数年の傾向として, 製紙業界では省エネルギー, 古紙の利用促進及び板紙の軽量化が進んでする。また， 生産性の向上を目的とした抄紙機の高速化, 用水使用 のクローズド化が進んでいる。

一方，板紙に対するニーズの多様化，高品質化がさ らに高まっている。このように状況変化に対応寸るた 紙力増強剤に対する依存度が高まり, 同時に使用量 も急增し, 紙力増強剤に対する改善が要求されている。

*第 4 回製紙技術セミナー講演

\section{2. 佐賀工場抄紙機設備能力一覧表}

当工場では, 産業用の各種板紙を製造している（表 1)。

\section{3. 当工場の現状の問題}

\section{1 操業上の問題点}

(1) 原料 $\mathrm{pH}$ アップ (填料の増加)

(2) 硫酸ばん土の増加

(3) 白水中の無機イオンの増加

(4) 原料の $\mathrm{pH} の$ 変動

（5）乾燥性の悪化（抄速ダウン）

(5) 紙力発現の低下

このような問題点により，現状の紙力剤処方（アニ 
表 1

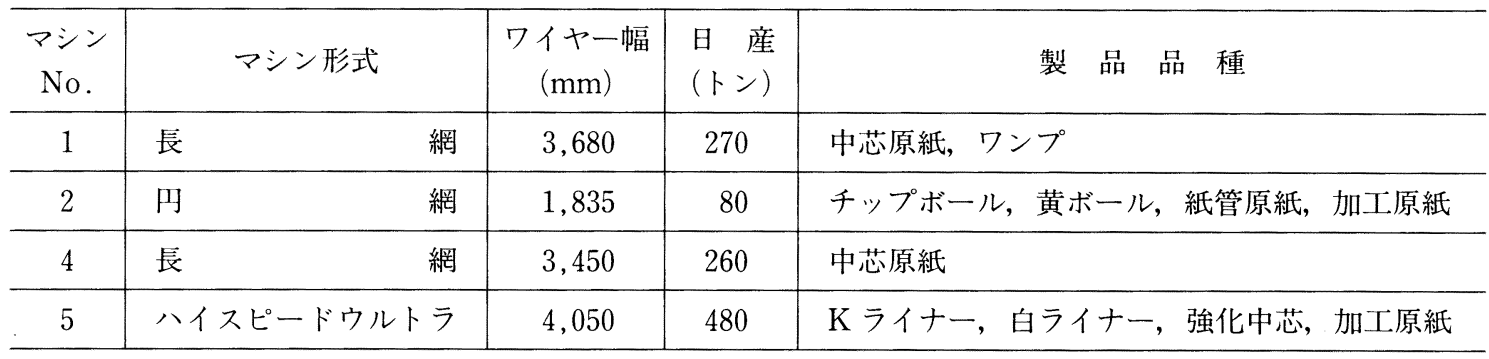

オン，マンニッヒの混合処方）では対応が困難になっ てきている。

\section{2 混合処方の問題点}

現状の操業上の問題点から整理してみると，以下の ようになると考えられる。

混合処方の問題点：

抄紙 $\mathrm{pH}$ 範囲が狭い（pH 4.5 5.5）（図 1)

高 $\mathrm{pH}$ 域（pH 5.5 以上）では効果が低い

硫酸ばん土を多く添加する必要がある

\section{3 所定 $\mathbf{p H}$ にするための硫酸ばん土必要量}

原料の違いによる所定 $\mathrm{pH}$ にするための硫酸ばん土 必要量は，図 2 で示される。

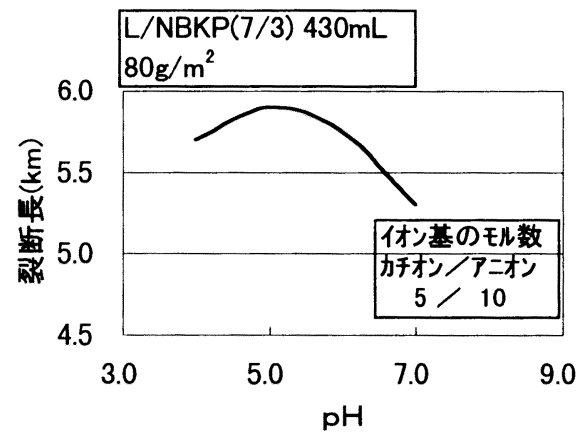

図 $1 \mathrm{pH}$ と両性 PAM の紙力効果の関係

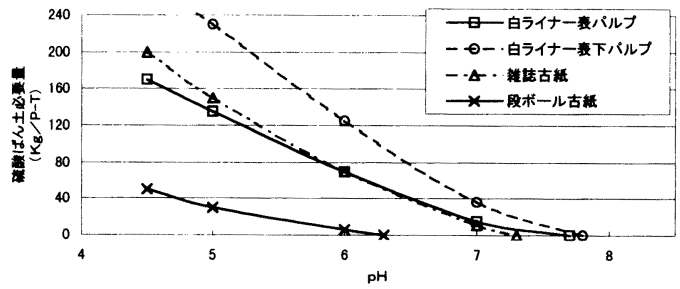

図 2 所定 $\mathrm{pH}$ にするための硫酸ばん土必要量

\section{4. 混合処方に替わる紙力剤の開発の基本的} 考え方

紙力剤の開発の基本的考え方（目標）：

(1)高 $\mathrm{pH}$ 域（pH 5.5 以上）でも，高いろ水性，竹 水効果が得られ乾燥性が向上寸ること

(2)紙力的に同コストで同等以上の効果がでること

(3)紙力剤増添加による抄紙系内の污れを減少できる こと

(4)全抄紙機，全抄物に対応できること

以上 4 点に決めて，取り組むことにした。

4.1 開発にあたってのテーブルテスト結果

紙力（比破裂強さ）向上について比較を行ったもの を図 3 に示した。

\section{2 紙力剤開発の経過}

(1)現行混合処方（アニオン十両性マンニッヒ）

(2) (アニオン十共重合) 万水, 乾燥性不良, 紙力不足

(3) (新共重合十両性マンニッヒ) 万水，乾燥性良好， 紙力同等

開発の検討経過として，始めに(2)の（アニオン十共

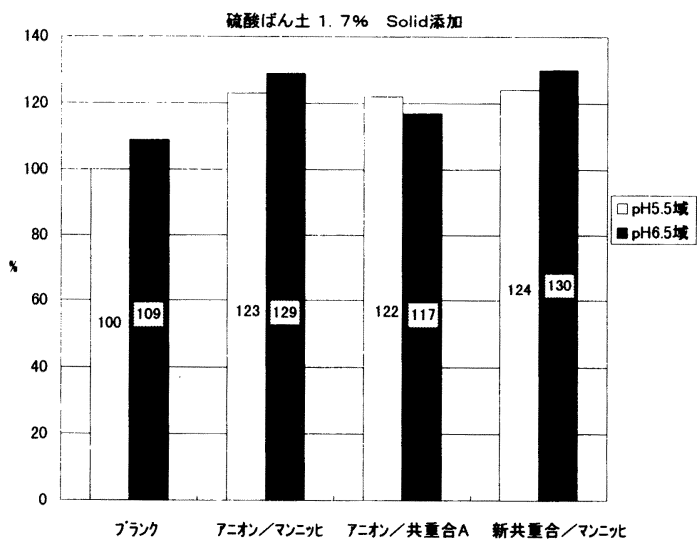

図 3 段古紙に対する紙力（比破裂強さ）効果 
重合) の混合処方でカチオン量，分子量等をいろいろ 変えてテストを行ったが効果が良くなかった。そこで (3)の両性マンニッヒを残し，アニオンの代替としてア ニオンリッチの共重合を使用する方法を行った。

その結果，万水性，乾燥性が良く紙力は同等のもの が得られた。これを混合処方と区別するために新混合 処方と称することにした。

\section{5. 混合処方と新混合処法の比較}

実機テスト結果をライナーと中芯について, 表 2, 表 3 に示した。

表 2 ライナーでの混合処方と新混合処方の比較

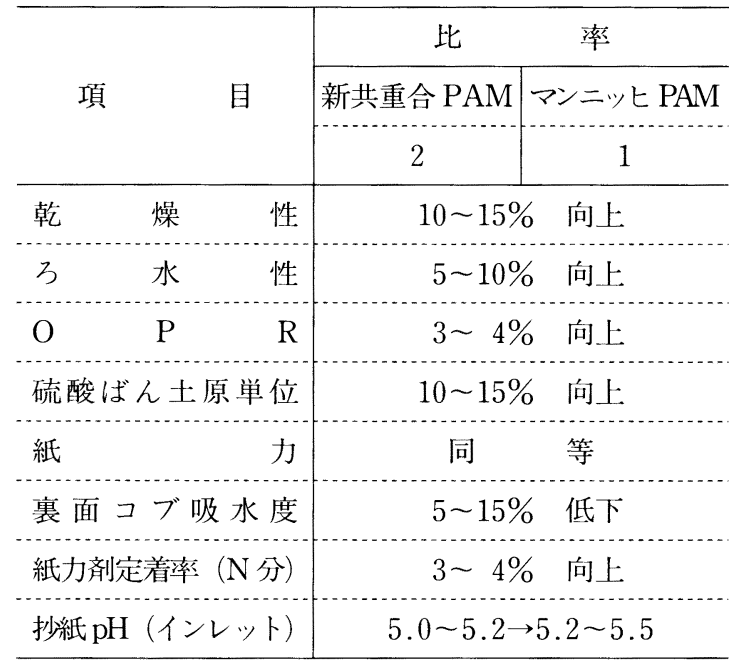

(紙力剤は同コストで添加)

表 3 中芯での混合処方と新混合処法との比較

\begin{tabular}{|c|c|c|c|c|}
\hline \multirow{3}{*}{ 項 } & \multirow{3}{*}{\multicolumn{2}{|c|}{ 目 }} & \multicolumn{2}{|c|}{ 比率 } \\
\hline & & & 新共重合 PAM & マンニッヒ PAM \\
\hline & & & 1.5 & 1 \\
\hline 乾 & 燥 & 性 & \multicolumn{2}{|c|}{ 5 $10 \%$ 向上 } \\
\hline ろ & 水 & 性 & \multicolumn{2}{|c|}{$5 \sim 10 \%$ 向上 } \\
\hline $\mathrm{O}$ & $\mathrm{P}$ & $\mathrm{R}$ & \multicolumn{2}{|c|}{$0.5 \sim 3 \%$ 向上 } \\
\hline \multicolumn{3}{|c|}{ 硫酸ばん土原単位 } & \multicolumn{2}{|c|}{$5 \%$ 向上 } \\
\hline & & 力 & 同 & 等 \\
\hline 裏面 & ブ & & 同 & 等 \\
\hline 紙力剂 & 着率 & & $3 \%$ & 向上 \\
\hline
\end{tabular}

（紙力剤は同コストで添加）

\section{6. 結果の考察}

実機テストの結果より

（1）乾燥性の向上

(2) 硫酸ばん土の削減ができる

（3）紙力剤同コスト添加で（20\%削減）同等紙力を 発現できる。

上記の結果がでているので，フリーネス，搾水及び 紙力剤の $\mathrm{pH}$ 域，ポリイオンコンプレックス (PIC) の構造について考察した。

\section{1 乾燥性の向上（フリーネスでの効果）}

乾燥性の向上について, フリーネスの面で比較を行 ったものを図 4, 図 5 に示した。

\section{2 乾燥性の向上（搾水性について）}

なぜ搾水性が良くなるかについて混合処方と新混合 処方の凝集形態の違いを推定として，図6に示した。

\section{3 硫酸ばん土の削減}

硫酸ばん土の削減ができるかについて紙力郕の $\mathrm{pH}$ 一活性カチオン量の関係を図7に示した。新混合処方 に使われている共重合 PAMのカチオンが広い $\mathrm{pH}$ 域 で効果を保っている。

\subsection{PIC（ポリイオンコンプレックス）の推定 構造について}

紙力郕の添加量減でも同等紙力を得ることができる ことについて PIC の推定構造より説明を試みる。

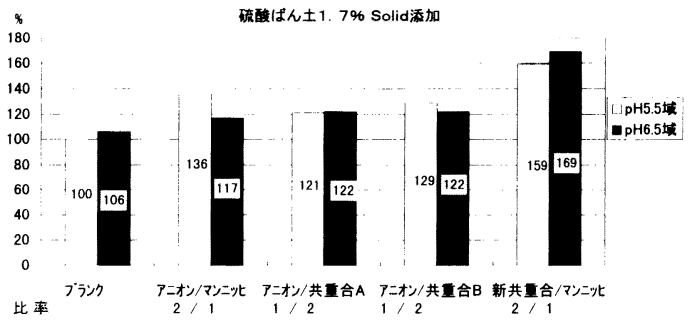

図 4 段古紙に対するろ水効果（フリーネス）

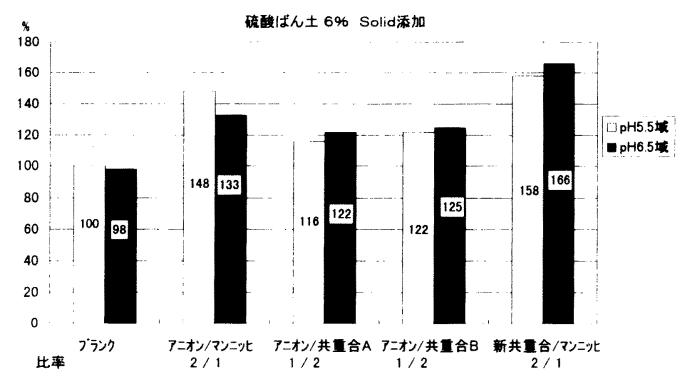

図 5 上白古紙に対するろ水効果（フリーネス） 
混合処方

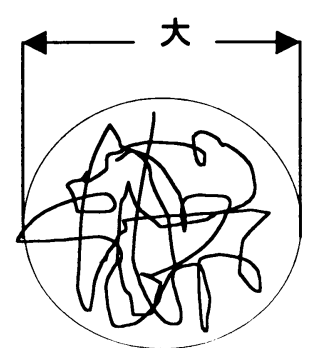

P | cの大きさ

\section{新混合処方}

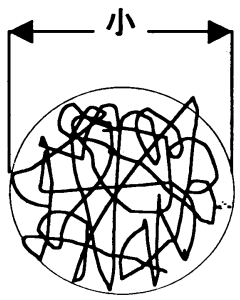

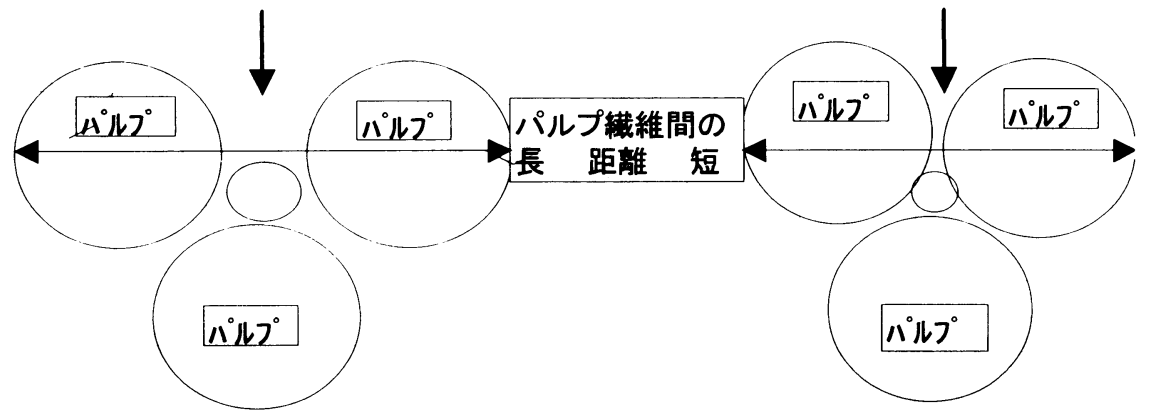

図 6 混合処方と新混合処方の凝集の形態

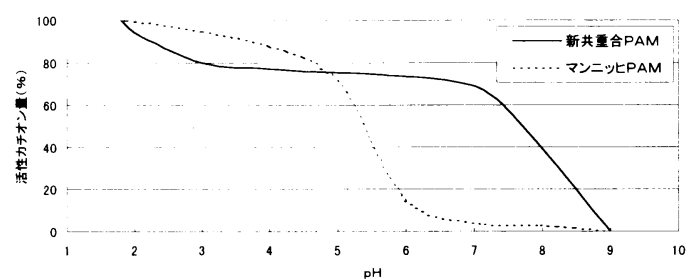

図 $7 \mathrm{pH}$ 一活性カチオン量

\section{4 .1 混合処方 PIC の推定構造}

図 8 に混合処方 PICの推定構造図を示す。硫酸ば ん土添加の効果を示す。このため, ある程度の硫酸ば ん土が必要なわけである。

\subsection{2 新混合処方 PIC の推定構造}

ここで使用される新共重合 PAM が

(1)広い $\mathrm{pH}$ 域でカチオン性を保持できる。

(2)ポリマーが分岐構造で高密度の高分子量である。 という特長を持っている。

新混合処方の PIC の推定構造を図 9 に示した。

混合処方のPICより, 硫酸ばん土の多量添加は必 要とせず強固で小さい PICを作る。結果的に, 高シ エアー, 高電解質下でも安定な構造を持ち, 紙力剤が 削減できると考える。

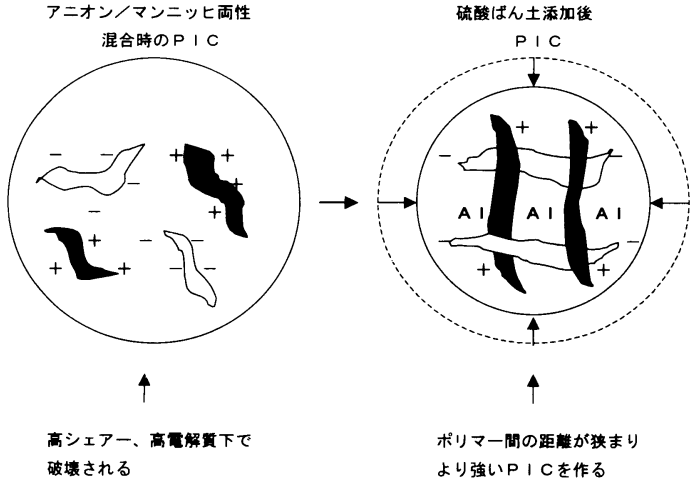

図 8 混合処方法 PIC の推定構造

\section{7. 新混合処方の特長}

現在までの実機抄造結果より，新混合処方の特長と して

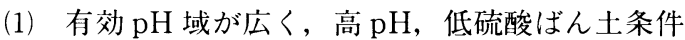
下でも, ろ水, 搾水効果が得られ, 乾燥性が向上 する。

(2) 層間強度のアップ

(3) OPRの向上。

ということが忍められた。 
マンニッヒ両性

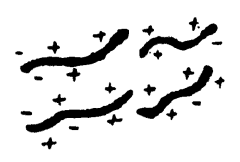

新共重合PAM

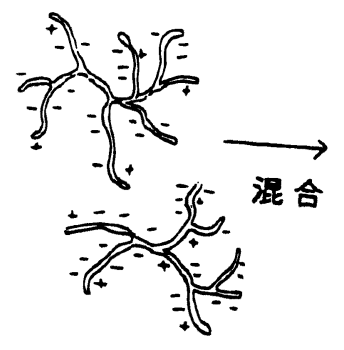

高シェアー
安定な桡造

新混合処方のP |C

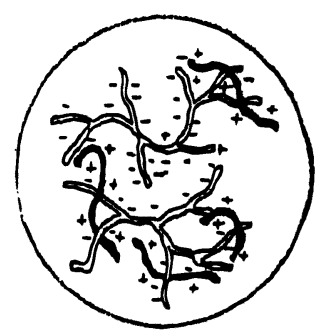

高雷解算下でも

図 9 新混合処方法 PIC の推定構造

\section{8. 今後の課題}

今回の発表では, 白ライナー, 強化中芯での結果を 述べたが他の抄紙機についても, 従来処方と同等以上 の乾燥性, 地合面での効果がみられた。今後の課題と して紙力発現性の更なる向上を目指し, 現在取り組み 中である。

\section{9. まと め}

板紙での分岐型紙力剤導入により, 白水中の無機イ オンの增加に対して一定の効果を見出したが，今後更 なる白水のクローズド化が進むものと思われる。工場 サイドでは, これに対応すべく, 技術, 設備, 方法の 改善を図りたい。 